\title{
Tolerance Levels of Peanut Varieties against Aspergillus flavus Infection
}

\author{
Frank Olwari*, Jenipher Bisikwa², Archileo Natigo Kaaya² and David Kalule Okello
}

${ }^{1}$ Department of Agricultural Production, College of Agricultural and Environmental Sciences, Makerere University, P.O. Box 7062 Kampala, Uganda

${ }^{2}$ School of Food Technology, Nutrition and Bioengineering, Department of Food Technology and Human Nutrition Makerere University, P.O. Box 7062 Kampala, Uganda

\begin{abstract}
Peanuts (Arachis hypogaea L.) are usually infected by Aspergillus flavus and A. parasiticus during pre and post-harvest periods subsequently resulting in aflatoxin contamination. Thirteen peanut varieties were evaluated for kernel and pod colonization and infection by $A$. flavus in this study. The pods and kernels were examined under a microscope for $A$. flavus infection levels. Differences in mean ratings of infected peanut kernels and pods were observed after 10 days of artificial inoculation and incubation. More differences were observed among the mean ratings of peanut kernels and pods with invisible mycelial surface coverage. However, these mean differences were not statistically significant $P \geq 5$. Peanut varieties with the biggest mean ratings of kernels and pods with invisible mycelia or no visible sign of infection and smallest mean ratings of infected pods and kernels could be considered tolerant to $A$. flavus colonization and infection in this study. Therefore, there is a need to promote the cultivation of these varieties by farmers as they have low levels of infection and subsequently low level of aflatoxin contamination. The peanut varieties with the lowest mean ratings of kernels and pods with invisible mycelia which are considered to have good attributes warrant improvement through selection and breeding. This is because most farmers in Uganda store their peanuts in pod form which offers some protection against infection. In addition, peanut varieties with biggest mean ratings of kernels with invisible mycelia need to be promoted among traders since they are considered to have lower levels of $A$. flavus infection.
\end{abstract}

Keywords: Peanut; Aspergillus flavus; Mycelia; Aflatoxin; Contamination

\section{Introduction}

eanuts also known as groundunts (Arachis hypogea $\mathrm{L}$ ) are commonly infected by $A$. flavus and $A$. parasiticus during pre-harvest and postharvest periods [1]. A. flavus and A. parasiticus fungi attack peanuts when drying and under storage conditions subsequently resulting in aflatoxin contamination [2]. Furthermore, improper harvesting and storage practices also increases the levels of aflatoxin in peanuts [3]. The Aspergillus infection of peanuts during pre-harvest period is attributed to peanut pods being in direct contact with soil fungal populations [4]. In addition, high temperature, high relative humidity and insect damage also contribute to the high levels of pre-harvest infection [5].

Aflatoxin contamination of agricultural commodities leads to losses of the production especially in terms of costs of regulatory programmes designed to reduce risks to human and livestock health [6]. Therefore, in order to reduce aflatoxin contamination in peanuts and peanut based products, numerous approaches have been adopted by various countries. These aflatoxin management strategies include; adoption of good agronomic practices, proper harvesting and storage practices, chemical control, and biological control $[7,8]$.

Adopting resistant cultivars is considered the most effective and low-cost component of aflatoxin management programme [3]. Peanut varieties with differing concentrations of aflatoxin during and after infection by A. flavus have been reported [9-12]. Four resistance strategies to A. flavus and A. parasiticus have been extensively studied [13-16]. And these four resistance strategies are; seed colonization by A. flavus (SCAF), field resistance to seed colonization by A. flavus (FSCAF), pre-harvest resistance to A. flavus contamination (PAC) and resistance to aflatoxin production. The need for empirical evaluation of the different peanut varieties to A. flavus infection tolerance levels and lack of known varieties resistant to aflatoxin contamination, justified this study Therefore, recommended agronomical practices, postharvest storage strategies and good processing practices need to be promoted among farmers, traders, processors and other stakeholders in order to reduce the level of aflatoxin contamination.

The objective of this study was to evaluate the peanut kernels and pod shell against $A$. flavus infection. The pod-shell and kernel resistance to $A$. flavus infection is related to the combination of physical and chemical characteristics of the seed testa [3], while the resistance to pod shell penetration is thought to be related to the pod shell structure (reticulation), thickness and hardiness [13]. Other research findings by Kushalappa et al. [17] show that pod resistance to A. flavus invasion was associated with undamaged peanut shells in addition to the presence of antagonistic fungal and bacterial microflora.

\section{Material and Methods}

The experiment materials comprising of 13 peanut varieties as presented in Table 1.

\section{Experimental design}

The experimental design was a Completely Randomized Design (CRD) with 3 replicates and each replicate comprised 10 health plump kernels and 10 unshelled peanut pods. The evaluation of the levels of $A$. flavus colonization of peanuts was rated as percentage mycelial growth surface coverage on peanut kernels and pods. The different levels of $A$. flavus tolerance against the different peanut varieties experiment was

${ }^{*}$ Corresponding author: Frank Olwari, Department of Agricultural Production College of Agricultural and Environmental Sciences, Makerere University, P.O. Box 7062 Kampala, Uganda, Tel: +256712719682; E-mail: folwari@agric.mak.ac.ug

Received July 24, 2013; Accepted August 24, 2013; Published August 29, 2013

Citation: Olwari F, Bisikwa J, Kaaya AN, Okello DK (2013) Tolerance Levels of Peanut Varieties against Aspergillus flavus Infection. J Plant Pathol Microb 4: 195 doi:10.4172/2157-7471.1000195

Copyright: (ㅇ 2013 Olwari F, et al. This is an open-access article distributed under the terms of the Creative Commons Attribution License, which permits unrestricted use, distribution, and reproduction in any medium, provided the original author and source are credited. 


\begin{tabular}{|c|c|c|c|}
\hline Varieties & Maturity (days) & Year of release & Other remarks \\
\hline Red beauty & $90-100$ & 1966 & $\begin{array}{l}\text { Multiline of Red } \\
\text { Valencia }\end{array}$ \\
\hline Igola & $125-130$ & 1995 & Spanish, tan seeded \\
\hline Serenut 1 & $100-110$ & 1998 & Virginia, Red Seeded \\
\hline Serenut 2 & $100-110$ & 1998 & Virginia, Tan \\
\hline Serenut 3 & $90-100$ & 2002 & Spanish, Red Seeded \\
\hline Serenut 4 & $90-100$ & 2002 & Spanish, Tan \\
\hline Erudurudu & $100-110$ & Landrace & Valencia \\
\hline Acholi white & $80-90$ & 1966 & Valencia \\
\hline Gweri nut & $100-110$ & 1969 & $\begin{array}{c}\text { Red } \\
\text { Manyema,Venezuela }\end{array}$ \\
\hline Entry 99566 & $100-110$ & 2010 & Spanish, tan seeded \\
\hline Entry 99527 & $90-100$ & Advanced line & Spanish, tan seeded \\
\hline Entry 99528 & $90-100$ & Advanced line & Spanish, red seeded \\
\hline Entry 93535 & $90-100$ & 2010 & Spanish, red seeded \\
\hline
\end{tabular}

Table 1: Peanut varieties used in the experiment.

conducted at the Department of Food Science Microbiology laboratory, Makerere University.

\section{Preparation of the inoculums}

Peanut kernels were sterilized using $10 \%$ sodium hypochlorite and assayed in triplicates on malt extract agar for 3 days according to Pitt and Hocking [18]. A. flavus was isolated and identified morphologically and cultured on Aspergillus flavus/ parasiticus (AFPA) selective nutrient media $[18,19]$. Pure A. flavus fungi were obtained by sub-culturing using the aid of a sterile swab which was streaked over the entire malt extract on the petridish and incubated at $25^{\circ} \mathrm{C}$ until substantial sporulation was observed.

The A. flavus spores were washed off the Petri -dishes, dissolved in 1 litre of sterile distilled water in an Erlenmeyer flask and 2 drops of tween were added to ensure a uniform distribution of the spores. The $1 \times 10^{6}$ spores per litre were used as inocula and were estimated using a haemacytometer.

\section{Inoculation of Peanut varieties with AspergilMs spores}

Intact pods were selected at random, shelled and 10 healthy kernels from each sample lot in triplicates were assayed by direct plating technique for internal fungal infection [18,20,21]. The kernels were surface sterilized for 1 minute with sodium hypochlorite $(10 \%$ commercial bleach, Jik ${ }^{\circledR}$, Rickitt Benckiser, East Africa Ltd). They were rinsed 3 times with sterile water and hydrate to $20 \%$ moisture content by soaking in sterile distilled water for 10 minutes.

The 10 kernels and pod shells were aseptically placed in sterile Petri dishes of $9 \mathrm{~cm}$ diameter in triplicates and $1 \mathrm{ml}$ of A. flavus spores $\left(1 \times 10^{6}\right.$ spores/per litre) in distilled water added. In addition, pods and kernels were washed with sterile distilled water as a control since sodium hypochlorite could compromise the integrity of seed testa constituents which are soluble in alkaline solutions [22]. The kernels and pods were rolled gently in the Petri dishes using a sterile inoculation loop to spread the inoculum evenly over the surface of kernels and pods. The Petri dishes were arranged in the semi rigid plastic boxes (chamber) with fitting lids to ensure constant humidity. The lids were sealed with cello tape to prevent cross contamination with open-air microorganisms and placed in an incubator at $25^{\circ} \mathrm{C}$ in darkness for 10 days. After 10 days of incubation, the kernels were examined under a Nikon stereoscopic microscope for A. flavus infection.

\section{Data collection and analysis}

The data was collected 10 days after artificial inoculation and incubation. A 1 to 5 score scale according to Strange [23] with some modification was used to score Aspergillus flavus infection on different peanut, where; $1=$ invisible mycelial growth, $2=1$ to $20 \%$ mycelial growth surface coverage on the kernel, $3=21$ to $50 \%$ mycelial growth surface coverage on the kernel, $4=51$ to $70 \%$ mycelial growth surface coverage on the kernels, $5=71$ to $100 \%$ mycelial growth surface coverage on peanut kernels and shells. The data was analysed using GenStat discovery edition 3 and the means were separated by Fisher's protected t-test [24].

\section{Results and Discussion}

The results of pods and kernels revealed that none of the kernels and pods from all the 13 peanut varieties was immune to A. flavus infection. However, kernels and pods of the 13 peanut varieties exhibited differences in mycelial growth surface coverage under different treatments as presented in Table 2 and 3. The differences in mycelial growth surface coverage were probably attributed to differences in physical and chemical features of the seed-coat, pod-shell thickness and reticulation. LaPrade et al. [25] and Liang et al. [26] reported that peanut resistance to A. flavus and subsequent aflatoxin contamination could have been attributed to seed coat thickness, permeability and seed testa constituents.

Among the peanut varieties sterilized with $10 \%$ sodium hypochlorite, the following varieties had invisible mycelia and highest mean ratings of kernel; Acholi white with 1.00, entry 99527 with 0.76, Serenut 1 and Serenut 2 with 0.62 each as shown in Table 3. The higher mean ratings of kernels with invisible mycelia (Acholi white, entry 99527, Serenut 1 and Serenut 2) are probably attributed to differences in the physical barriers constituents such as wax and cutin in the peanut seed testa which were sparingly soluble in sodium hypochlorite. Wotton and Strange [27] and Liang et al. [28] reported that wax and cutin isolated from seed testa play an inhibitory role against $A$. flavus colonization and invasion of peanut kernels.

\begin{tabular}{|c|c|c|c|c|c|}
\hline Varieties & $\begin{array}{c}\text { Invisible } \\
\text { Mycelia growth }\end{array}$ & $\mathbf{1 - 2 0} \%$ & $\mathbf{2 1 - 5 0 \%}$ & $\mathbf{5 1 ~ - 7 0 \%}$ & $\mathbf{7 1 - 1 0 0 \%}$ \\
\hline Red beauty & 0.49 & 0.15 & 5.00 & 2.00 & 3.00 \\
\hline Igola & 0.49 & 1.03 & 5.50 & 3.50 & 1.00 \\
\hline Serenut 1 & 0.62 & 1.00 & 4.50 & 3.50 & 1.33 \\
\hline Serenut 2 & 0.62 & 0.50 & 2.21 & 3.50 & 3.50 \\
\hline Serenut 3 & 0.01 & 0.78 & 3.40 & 4.00 & 2.50 \\
\hline Serenut 4 & 0.50 & 0.40 & 4.00 & 3.00 & 2.50 \\
\hline Erudurudu & 0.12 & 0.65 & 4.50 & 2.00 & 3.50 \\
\hline Acholiwhite & 1.00 & 1.50 & 1.50 & 2.50 & 3.50 \\
\hline Gwerinut & 0.13 & 0.34 & 2.50 & 1.50 & 6.00 \\
\hline 99566 & 0.38 & 0.34 & 1.69 & 1.50 & 7.00 \\
\hline 99527 & 0.76 & 1.19 & 4.50 & 1.50 & 2.00 \\
\hline 99528 & 0.12 & 0.10 & 2.50 & 4.00 & 3.50 \\
\hline 93535 & 0.28 & 0.34 & 5.50 & 1.33 & 3.50 \\
\hline Total & 5.52 & 8.32 & 47.30 & 33.83 & 42.83 \\
\hline LSD (0.05) & 1.34 & 2.02 & 11.48 & 8.21 & 10.40 \\
\hline CV, (\%) & 17.80 & 26.83 & 50.83 & 36.35 & 46.04 \\
\hline
\end{tabular}

Scored on $1-5$ rating scale where $<1=$ Invisible mycelial growth; $2=1-20 \%$ mycelia growth coverage on the kernel surface; $3=21-50 \%$ mycelial growth coverage on the kernel surface; $4=51-70 \%$ mycelial growth coverage on the kernel surface; $5=71$ $100 \%$ mycelial growth coverage on kernel surface.

Table 2: Mean ratings of infected peanut kernels sterilized with $10 \%$ sodium hypochlorite. 


\begin{tabular}{|c|c|c|c|c|c|}
\hline Varieties & Invisible mycelia & $\mathbf{1 - 2 0} \%$ & $\mathbf{2 1 - 5 0 \%}$ & $\mathbf{5 1 - 7 0 \%}$ & $\mathbf{7 1 - 1 0 0 \%}$ \\
\hline Red beauty & 2.00 & 1.50 & 1.00 & 4.50 & 1.00 \\
\hline Igola & 1.50 & 3.00 & 2.50 & 2.50 & 0.51 \\
\hline Serenut 1 & 2.50 & 2.50 & 2.50 & 2.50 & 0.37 \\
\hline Serenut 2 & 0.50 & 1.50 & 2.50 & 3.00 & 2.50 \\
\hline Serenut 3 & 0.00 & 4.00 & 2.00 & 3.00 & 1.00 \\
\hline Serenut 4 & 1.00 & 1.20 & 3.50 & 1.50 & 3.50 \\
\hline Erudurudu & 0.50 & 1.45 & 0.97 & 6.00 & 2.50 \\
\hline Acholi white & 3.00 & 2.00 & 2.00 & 3.00 & 1.62 \\
\hline Totals & 11.00 & 17.15 & 16.97 & 26.00 & 13.00 \\
\hline LSD & 0.09 & 0.14 & 0.14 & 0.21 & 0.11 \\
\hline CV, (\%) & 20.00 & 31.11 & 31.11 & 46.67 & 24.44 \\
\hline
\end{tabular}

Scored on $1-5$ rating scale where $<1=$ Invisible mycelial growth; $2=1-20 \%$ mycelia growth coverage on the pod shell surface; $3=21-50 \%$ mycelial growth coverage on the pod shell surface; $4=51-70 \%$ mycelial growth coverage on the pod shell surface; $5=71-100 \%$ mycelial growth coverage on pod shell surface.

Table 3: Mean ratings of infected pods sterilized with $10 \%$ sodium hypochlorite.

However, under 71-100\% mycelial growth surface coverage on the kernels category, Igola with 1.00 , Serenut 1 with 1.10 , entry 99527 with 2.00 , Serenut 3 and Serenut 4 with 2.50 had the smallest mean ratings of infected kernels when sterilized with $10 \%$ sodium hypochlorite as observed in Table 2. The smaller mean ratings of infected kernels could have been due to the compact arrangement of palisade-like layers of the seed testa. The compact palisade-like layers of seed testa were reported to have reduced $A$. flavus colonization, invasion and subsequent infection of peanut kernels $[29,30]$.

In general, the total mean ratings of kernels with invisible mycelia washed with sterile distilled water was higher than the total mean ratings of kernels sterilized with $10 \%$ sodium hypochlorite. However, the total mean ratings of infected kernels under $71-100 \%$ category which were washed with sterile distilled water were smaller than the total mean of infected kernels. The differences in total mean ratings of kernels with invisible mycelia and infected kernels is probably due to the dissolving action of sodium hypochlorite on the seed coat constituents especially the soluble wax and cutin in the alkaline solution of sodium hypochlorite whereas water has a minimum effect as it is neutral.

Sodium hypochlorite has a bleaching and dissolving effect on the soluble wax and cutin constituents which are embedded in the seed coat matrices and which are deposited on the external surfaces of the seeds [31]. Therefore by using $10 \%$ sodium hypochlorite as a sterilization agent, the seed protective mechanism against pathogen is broken down, consequently resulting in higher infection levels.

Among the varieties sterilized with $10 \%$ sodium hypochlorite, the biggest mean ratings with invisible mycelia was in Acholi white with 3.00 , Red beauty with 2.00 and 1gola with 1.50 . Whereas Serenut 1 with 0.37 , Igola with 0.57 , Serenut 3 and Red beauty with 1.00 each of infected pods had the smallest mean ratings under $71-100 \%$ category as is presented in Table 3 below. The higher mean ratings of pods with invisible mycelial and the smaller mean ratings of infected pods could have been attributed to breakdown of resistance of pods against $A$. flavus colonization. According to Kushalappa et al. [32] pre-inoculation sodium hypochlorite sterilization of different peanut genotypes reduced their resistance against $A$. flavus infection. The sterilization action of sodium hypochlorite was reported to eliminate the antagonistic microflora which is responsible for peanut varietal resistance [33,34].

\section{Conclusion}

The results from this experiment show differences in the mean ratings of infected peanut kernels and pods. Differences were also observed in the mean ratings of peanut kernels and pods with no visible infection or invisible mycelial growth, however, these differences were not statistically significant $P \geq 5$. Peanut varieties with the highest mean ratings of kernels and pods with invisible mycelia and those with the smallest mean ratings of kernels and pods infected with $A$. flavus could be considered tolerant to A. flavus colonization and infection in this study. Since farmers store peanuts in kernel and pod form, peanut varieties with the biggest mean ratings of kernels (Entry 99527, Serenut 1, Serenut 2, Red beauty, Acholi white and Igola) with invisible mycelia and the varieties with the smallest mean ratings of infected kernels (Igola, Serenut 1, Serenut 2 and entry 99527) should be promoted as an aflatoxin management strategy. Therefore there is a need to carry out molecular elucidation for the cause of differences in the levels of A. flavus infection of the peanut varieties which have the biggest mean ratings of kernels with invisible mycelia and those with the smallest mean ratings of infected kernels. In addition, desirable peanut varieties with smaller mean ratings of invisible mycelia and those with the biggest mean ratings of infection by $A$. flavus warrant improvement by research.

\section{Acknowledgement}

This study was funded by Carnegie Corporation of New York. We acknowledge Makerere University College of Agricultural and Environmental Sciences and National Agricultural Research Organization/Groundnut Improvement Programme for providing us the necessary facilities for the experiments.

\section{References}

1. Kumar CA, Priyanka K (2010) Management of mycotoxin contamination in preharvest and post-harvest crops: Present Status and Future Prospects. Journal of Phytothology 2: 37-42.

2. Payne GA (1998) Process of contamination by aflatoxin-producing fungi and their impact on crops, In Sinha KK and Bhatnagar D (eds.) Mycotoxins in Agriculture and Food Safety. Marcel Dekker Inc, New York, USA.

3. Xue HQ, Iselib TG, Stalker HT, Payne GA, Obrian G (2004) Evaluation of Arachis species and interspecific tetraploid lines for resistance to aflatoxin production by Aspergillus flavus. Peanut Science 31: 134-141.

4. Horn BW, Dorner JW (1998) Soil populations of Aspergillus species from section Flavi along transect through peanut-growing regions of the United States. Mycologia 90: 767-776.

5. Cotty PJ, Garcia RJ (2007) Influence of climate o aflatoxin producing fungi and aflatoxin contamination. Int J Food Microbiol 119: 109-115.

6. Craufurd PQ, Prasad PVV, Waliyar F, Taheri A (2006) Drought, pod yield, preharvest Aspergillus infection and aflatoxin contamination on peanut in Niger Field Crop Research 98: 20-29.

7. Dorner JW, Cole RJ (2002) Effects of application of non-toxigenic strains of Aspergillus flavus and $A$. parasiticus on subsequent aflatoxin contamination of peanuts in storage. Journal of Stored Products Research 38: 329-339.

8. Hell K, Cardwell KF, Setamou M, Poehling HM (2000) The influence of storage practices on aflatoxin contamination in maize in four agroecological zone of Benin, West Africa. J Stored Prod Res 36: 365-382.

9. Mehan VK, MCdonald D, Ramakrishna N, William JH (1986) Effects of genotype and date of harvest on infection of peanut seed by Aspergillus flavus and subsequent contamination with aflatoxin. Peanut Science 13: 46-50.

10. Mehan VK, MCdonald D, Haravu LJ, Jayanthi S (1991) The peanut aflatoxin problem: review and literature database. International Crops Research Institute for Semi-Arid Tropics, Patancheru, India.

11. Dange SRS, Prasad SR (1989) Aflatoxin production in seeds of selected peanut cultivars. Bulletin Grain Technology 27: 60-62.

12. Ghewande MP, Nagaraj G, Reddy PS (1989) Aflatoxin research at the Nationa Research Center for Peanut. McDonald D and Mehan VK (eds.) Aflatoxin Contamination of Peanut (Proceedings of International Workshop), ICRISAT Center, Patancheru, AP, India. 
Citation: Olwari F, Bisikwa J, Kaaya AN, Okello DK (2013) Tolerance Levels of Peanut Varieties against Aspergillus flavus Infection. J Plant Pathol Microb 4: 195 doi:10.4172/2157-7471.1000195

13. Zambettakis CF (1975) Study of the contamination of several of peanut by Aspergillus flavus. Oleagineus 30: 161-167.

14. Mehan VK, MCdonald D (1980) Screening for resistance to Aspergillus invasion and aflatoxin production in peanuts. ICRISAT Peanut Improvement Programme Occasional Paper 2. Patacheru, AP, India.

15. Davidson JI, Hill JRRA, Cloe JR, Mixon AC, Henning RJ (1983) Field performance of two peanut cultivars relative to aflatoxin contamination. Peanut Science 10: 43-47.

16. Holbrook CC, Kvien RKS, Wilson DM, Hook JE (2000) Pre-harvest aflatoxin contamination in drought tolerant and intolerant peanut. Peanut Science 27 $45-48$

17. Kushalappa AC, Bartz JA, Norden AJ (1976) Influence of the shell on colonization of intact peanut (Arachis hypogea) pods and seeds of different breeding lines by Aspergillus flavus (In Proceedings of American Phytopathology Society) 3 : $255-262$.

18. Pitt JI, Hocking AD (1999) Fungi and food spoilage. (3rdedn), Chapman and Hall, London, UK.

19. Klich MA, Samson RA (2009) Member of the ICPA (International Commission on Penicillium and Aspergillus). Aspergillus Reference Cultures.

20. ISTA (International Seed Testing Association) (1996) Internal rules for seed testing rules. Seed Science and Technology 24: 335.

21. Liang XQ, Holbrook CC, Lynch RC, Guo BZ (2005) $\beta-1,3-$-Glucanase activity in peanut seeds (Arachis hypogaea) is induced by inoculation with Aspergillus flavus and Copuriflies with a conglutun-like protein. The American Phytopathological Society 95: 5-10.

22. Khaef N, Sadeghi H, Taghvaei M (2011) Effects of New Strategies for Breaking Dormancy of 2 Annual Medics (Medicago scutellata and Medicago polymorpha. American-Eurasian Journal of Agricultural and Environmental Science 11: 626632

23. Strange NR (2003) Introduction to plant pathology. Published by Wiley and Sons Ltd UK.
24. Uriah N, Ibeh IN, Oluwafemi $F$ (2001) A study on the impact of aflatoxin on human reproduction. African Journal of Reproductive Health 106: 106-110.

25. Laprade JC, Bartz JA, Norden AJ, Demuynk TJ (1973) Correlation of peanut seed-coat surface wax accumulations with tolerance to colonization by Aspergillus flavus. Proceedings of American Peanut Research and Education Association 5: 89-94.

26. Liang XQ, Zhou GY, Pan RZ (2003) Study on the relationship of wax and cutin layers in peanut seeds and resistance to invasion and aflatoxin production by Aspergillus flavus. Journal of Tropical and Subtropical Botany 11: 11-14.

27. Wotton HR, Strange RN (1987) Increased susceptibility and reduced phytoalexin accumulation in drought-stressed peanut kernels challenged with Aspergillus flavus. Appl Environ Microbiol 53: 270-273.

28. Liang XQ, Luo M, Guo BZ (2006) Resistance mechanisms to Aspergillus flavus infection and aflatoxin contamination in peanut (Arachis hypogaea). Plant Pathology Journal 5: 115-124.

29. Taber RA, Pettit RE, Benedict CR, Dieckert JW, Kertring DL (1973) Comparison of Aspergillus flavus tolerant and susceptible lines. Light microscope investigation. American Peanut Research. Education Association 5: 206-223.

30. Gradziel TM, Wang D (1994) Susceptibility of California almond cultivars to aflatoxigenic Aspergillus flavus. Horticultural Science 29: 33-35.

31. Pinto RJJ, Yephremov A (2009) Surface lipids and plant defenses. Plant Physiology and Biochemistry 47: 540-549.

32. Kushalappa AC, Bartz JA, Norden AJ (1979) Susceptibility of pods of different peanut to Aspergillus flavus group fungi. Phytopathology 69: 159-162.

33. Atkinson TG, Neal JL, Larson R I (1975) Genetic control of the rhizosphere microflora of wheat. In: Bruehl GW (ed.) Biology and control of soil-borne plant pathogens. American Pathologological Society, St. Paul, MN, USA.

34. Jackson CR (1968) A field study of fungal association on peanut fruit. Georgia Agricultural Experimental Station Bulletin 26: 29-42. 